\title{
Impact of lower urinary tract symptoms on quality of life among patients with chronic heart failure
}

\author{
Taher Y Hableh, Mimi M Mekkawy, Ahmed M Obiedallah, Sahra Z Azer. \\ Clinical Instructor ( Sana'a-Yemen) Faculty of Nursing, Lecturer Assiut University, \\ Assistant Prof. of medical-surgical Nursing (Adult Nursing), Faculty of Nursing, Lecturer Assiut University, \\ Lecturer of internal medicine, Faculty of Medicine, Assiut University, \\ Lecturer of medical-surgical Nursing (Adult Nursing), Faculty of Nursing, Assiut University,
}

\begin{abstract}
Aim of the study: is to determine the impact of lower urinary tract symptoms on quality of life among patients with chronic heart failure. Subjects and methods Descriptive research designs were utilized in this study. The study sample was composed of one hundred adult patients attending cardiac outpatient clinics male and female, at Assuit University Hospital suffering from chronic heart failure. Study Data collected by utilizing the designed interview questionnaire. Demographic data, assessment sheet of lower urinary tract and World health organization quality of life. The study was done in period of 6 months from November /2013 to April /2014. Results: The results reveals that $70 \%$ of the patient in the study suffer from frequency urination, $41 \%$ suffer from urinary incontinence, $70 \%$ of them have urgency, $72 \%$ of the patients have nocturia, In relationship between quality of life and urinary tract symptoms there is a strong correlation $(\mathrm{r}=0.89)$ and significant statistically difference at $\mathrm{p}$. value $<0.01$.

Conclusion and Recommendations: lower urinary tract symptoms have effect on the quality of life among patients with heart failure and there is a strong correlation. So, patients should be provided with sufficient information about urinary tract symptoms and health education of quality of life.
\end{abstract}

\section{Keywords: chronic heart failure, quality of life \& lower urinary tract symptoms.}

\section{Introduction}

Chronic heart failure (CHF) is a complex clinical syndrome that can result from any structural or functional cardiac disorder that impairs the ability of the heart to sufficiently pump blood through the circulation (Schulze, 2008). Chronic heart failure is a major public health problem. It is estimated that there are nearly 23 million people with heart failure worldwide. CHF is a leading cause of morbidity, hospitalizations, disability, and death. Furthermore, the costs of care and treatment of CHF constitute a considerable burden for healthcare (Zarrinkoub et al., 2013).

In Egypt, according to national field survey in 2008, the prevalence of chronic heart failure based upon clinical manifestations and poor left ventricular systolic function was present in $1.3 / 1000$ of non hypertensive patients \& 9.6/1000 of hypertensive patients (Aroussy, 2008).

In Assiut University Hospital; approximately (264) cases of patients with chronic heart failure (male \& female) was admitted to cardiac medical department (Hospital record, 2012).

For clinical manifestations, patients with chronic heart failure may suffer signs and symptoms of both left and right ventricular failure. Left-sided heart failure; pulmonary congestion which causing pulmonary interstitial edema, and impaired gas exchange, dyspnea, cough, pulmonary crackles, and low oxygen saturation level. Right-sided heart failure; include edema of the lower extremities, hepatomegaly, ascites, anorexia, nausea and weakness (Smeltzer et al., 2010).

Up to $50 \%$ of chronic heart failure patients suffer from lower urinary tract symptoms. Urinary frequency, urgency and incontinence are extremely bothersome, while nocturnal symptoms may disrupt sleep and quality of life. The medications are used to treat heart failure may also indirectly provoke or exacerbate urinary symptoms (Tannebaun and Johnelly, 2013).

Quality of life is impaired in chronic heart failure (CHF), resulting in considerable impact on patients' daily activities, more severe impairment of physical and psychosocial functioning (Francis et al., 2010). Furthermore, Lower urinary tract symptoms interfere with daily activities, and hence may have the greatest negative impact on the patient's quality of life, patients' mental and physical health status due to decreased sleep quality (Kwong, 2010).

Although there is no universal description of Quality Of Life (QOL), it is sometimes described as a wellness resulting from a combination of physical, functional, emotional and social factors. Chronic conditions affect the QOL of adult people and contribute to disability and reduce their ability to live independently (Canbaz et al., 2003). 


\section{Significance of the study}

This study was the first study in Assiut University Hospital. The current study provides information about assessment effect of lower urinary tract symptoms on quality of life among patients with chronic heart failure. The important of this study is to determine the relation between a chronic heart failure and lower urinary symptoms. This study helps nursing staff to provide high quality health care to such group of patients.

\section{Aims of the study}

This study aim is to determine the impact of lower urinary tract symptoms on quality of life among patients with chronic heart failure.

\section{Research question}

Do lower urinary tract symptoms have effect on the quality of life among patients with chronic heart failure?

\section{Subjects and Methods}

\section{Research design}

Descriptive research designs were utilized in this study.

\section{I-Technical design}

It includes study setting, subjects, and tools of data collection.

\section{Study setting}

The study was conducted in cardiac out patient's clinics at Assiut University Hospital.

\section{Study subjects}

The study sample was composed of one hundred adult patients. The convenience sample of patients attending cardiac outpatient clinics male and female, at Assuit University Hospital suffering from chronic heart failure was chosen for conducting the study. Data collected by utilizing the designed interview questionnaire sheet. The data collecting of this study was done in period of 6 months.

\section{Tools of data collection}

The following tools were utilized by the researcher, tested and piloted to collect data pertinent to the study:-

Tool (I): Structured Interview questionnaire Sheet: (Annex I)

This sheet was developed by the researcher based on the best available of evidence. It includes 2 parts:

\section{Part 1: Demographic data.}

It was included the following items; patients age, gender, marital status, place of residence, occupation, level of education, medical diagnoses and duration of diseases.
Part 2: Assessment sheet of lower urinary tract symptoms;

This sheet was developed by the researcher based on best review of literature and included the following items: Storage symptoms and voiding symptoms.

Scoring system: Assessed the Information for symptoms of lower urinary tract this tools. It includes 15 items: divided into 9 questions (yes $=1, \mathrm{no}=0$ ), and 6 essay questions (less than $=1$, more than $=2$ ). Total score of the Information for symptoms of lower urinary tract $=25$.

Tool (II): World Health Organization Quality Of Life (WHOQOL): (Annex II)

The (WHOQOL): developed by WHO cited by (King \& hinds, 2004) The tool contains 54 questions over 5 broad domains of QOL within which 18 facets are covered to determine the quality of life. These 5 domains include physical, social, psychological, environment and perceived QOL, need of post lower urinary tract symptoms patients. Within each domain, several sub domains (facets) of QOL Summarize that particular domain of QOL. The 5 main domains are:

1-Physical health domain including: Activities of daily living, pain and discomfort, energy and fatigue, sleep and rest, work capacity, mobility and dependence on medication.

2-'Psychological domain including: Negative feeling, positive feeling, self esteem, spiritual, religious and personal beliefs.

3-Social relationships domain including: Personal relationships, social support and sexual activity).

4-Environment domain including: Physical environmental, safety and security, health and social care).

5- Perceived quality of life domain.

\section{Scoring system of quality of life}

The tools used for data collection in this study were all previously validated. The initial reliability analyses showed a correlation coefficient of more than 0.4-0.8. The validity of the tool ranged from $\mathrm{r}=0.244$ and 0.676 by (kuyken e, 1994). This Arabic version (translated by Professor Mohamed Abraham kamel, faculty of medicine, Alexandria, Egypt) was used in this study tool in Egypt by Mahmud, 2001 and modified by the researcher. The content validity of this tool was checked by expert professors in fields of medicine and nursing and correction was carried out accordingly for scoring for these variables, 3points lickert scale was adopted for the answer of each questions, which ranged, never (1)= low QOL, $(2)=$ moderate QOL, much(3)= high QOL. For pain and discomfort, the range in the sheets was from never (1), moderate (2), much (3). Each facet comprised 3 questions, i.e., the highest score for every facet was $0-9$. 


\section{Distribution of the scores in QOL tool}

\begin{tabular}{|l|c|c|}
\hline \multicolumn{1}{|c|}{ Domain } & items & Score \\
\hline Physical & 7 & 63 \\
Psychological & 4 & 36 \\
Social & 3 & 27 \\
Environmental & 3 & 27 \\
Perceived QOL & 1 & 9 \\
\hline Total score QOL & 18 & 162 \\
\hline
\end{tabular}

The scoring of these variables, a 3-point lickert scale on tables was adopted for the answer low $\mathrm{QOL}=0-3$, moderate $\mathrm{QOL}=4-6$, and high $\mathrm{QOL}=7-9$.

II-Operation design:- Data collection procedure was carried out in two phases:-

Phase 1: preparatory phase:

It includes reviewing of current literature and international related literature in the various aspects of the problems using text books, articles, and Journals in order to develop the study tools for data collection.

\section{Content validity}

The designed tools were judged on a jury for tools by (5) experts from medical and nursing staff. Their opinions were elicited regarding the tool format layout, consistency and scoring system.

\section{The pilot study}

A pilot study was conducted on first ten patients of the sample. The purpose of the pilot study was to detect any particular problem in the statements clarity, feasibility, and applicability of the tool. No change was done in the assessment sheet, so the patients selected for the pilot study were included in the main study.

\section{Phase 2: Implementation phase}

Data was collected at the cardiac out patient's clinics of Assiut University Hospital during the period from November /2013 to April /2014. The tools were all filled through interviewing patients. The purpose of the study was explained to the patients prior to answering the question. The study was carried out during morning shift for all available patients.

\section{III- Administrative design}

An official approval letter was secured from Nursing Faculty Dean at Assiut University to chairman of cardiology internal medicine department of Assuit University Hospital. Were setting before starting any data collection, with explanation for the study aim to obtain permission and cooperation for data collection.

\section{Ethical consideration}

Verbal permission with an explanation of the nature and aim of the study were obtained from clinical resident and head nurse at the cardiac out patient's clinics. Also, a verbal consent was obtained from each patient to be included in the study. Clarification of the nature and purpose of the study was done on initial interview with each patient. The investigator emphasized that the participation is absolutely voluntary. Confidentiality of the subject was certainly assured.

\section{IV- Statistical design}

Data collected and entered by Microsoft Excel 2010 program, the SPSS version (20) (Statistical package for social science) used for statistical analysis of data. Frequency used to calculate count and percentage of qualitative data (eg. gender) where descriptive used to obtained mean + standard deviation for quantitative data (eg. Age). Chi-square test used to test relation between qualitative variables where $\mathrm{T}$ test and ANOVA used to test relation between quantitative data. 


\section{Results}

Part I: Lower urinary tract symptoms \& patient's response related quality of life.

Table (1): Distribution of the samples as regards lower urinary tract symptoms $(n=100)$, , 2014.

\begin{tabular}{|c|c|c|}
\hline Items & No. & $\%$ \\
\hline \multicolumn{3}{|l|}{ Do you have urinated frequently } \\
\hline Yes & 70 & 70.0 \\
\hline No & 30 & 30.0 \\
\hline \multicolumn{3}{|c|}{ How many daytime urinary frequencies } \\
\hline Less than 10 times & 41 & 58.6 \\
\hline More than 10 times & 29 & 41.4 \\
\hline \multicolumn{3}{|l|}{ When getting urinary frequency } \\
\hline In the daytime & 25 & 35.7 \\
\hline In the night & 45 & 64.3 \\
\hline \multicolumn{3}{|c|}{ Do you have urinary incontinence } \\
\hline Yes & 41 & 41.0 \\
\hline No & 59 & 59.0 \\
\hline \multicolumn{3}{|c|}{ How long has suffered from urinary incontinence } \\
\hline Days & 12 & 29.3 \\
\hline Months & 21 & 51.2 \\
\hline Years & 8 & 19.5 \\
\hline \multicolumn{3}{|c|}{ How many times a day gets you urinary incontinence } \\
\hline Less than 3 times/day & 29 & 70.7 \\
\hline More than 3 times/day & 12 & 29.3 \\
\hline \multicolumn{3}{|c|}{ Do gets urinary incontinence during coughing, sneezing or carries heavy object } \\
\hline Yes & 30 & 30.0 \\
\hline No & 70 & 70.0 \\
\hline \multicolumn{3}{|l|}{ Do you have urgency } \\
\hline Yes & 70 & 70.0 \\
\hline No & 30 & 30.0 \\
\hline \multicolumn{3}{|l|}{ When you becoming urgency } \\
\hline Before treatment & 44 & 62.9 \\
\hline After treatment & 26 & 37.1 \\
\hline \multicolumn{3}{|l|}{ Do you have nocturia } \\
\hline Yes & 72 & 72.0 \\
\hline No & 28 & 28.0 \\
\hline \multicolumn{3}{|c|}{ How many times you have nocturia } \\
\hline Less than 3 times & 49 & 68.1 \\
\hline More than 3 times & 23 & 31.9 \\
\hline \multicolumn{3}{|l|}{ Do you have hesitancy } \\
\hline Yes & 38 & 38.0 \\
\hline No & 62 & 62.0 \\
\hline
\end{tabular}

Part II: Relationship between patient's characteristics and quality of life.

Table (2): Relationship between QOL level and patient's age, 2014

\begin{tabular}{|c|c|c|c|c|c|c|c|}
\hline \multirow{3}{*}{ Age } & \multicolumn{6}{|c|}{ QOL level } & \multirow{3}{*}{ P. value } \\
\hline & \multicolumn{2}{|c|}{$\operatorname{Low}(n=45)$} & \multicolumn{2}{|c|}{ Moderate $(n=38)$} & \multicolumn{2}{|c|}{ High $(n=17)$} & \\
\hline & No. & $\%$ & No. & $\%$ & No. & $\%$ & \\
\hline $18-<35$ years & 2 & 4.4 & 5 & 13.2 & 1 & 5.9 & \multirow{3}{*}{$0.011 *$} \\
\hline $35-<50$ years & 8 & 17.8 & 11 & 28.9 & 12 & 70.6 & \\
\hline 50 years and more & 35 & 77.8 & 22 & 57.9 & 4 & 23.5 & \\
\hline
\end{tabular}


Table (3): Relationship between QOL level and patient's education.

\begin{tabular}{|c|c|c|c|c|c|c|c|}
\hline \multirow{3}{*}{ Education level } & \multicolumn{6}{|c|}{ QOL level } & \multirow{3}{*}{ P. value } \\
\hline & \multicolumn{2}{|c|}{$\operatorname{Low}(n=45)$} & \multicolumn{2}{|c|}{ Moderate (n=38) } & \multicolumn{2}{|c|}{ High $(n=17)$} & \\
\hline & No. & $\%$ & No. & $\%$ & No. & $\%$ & \\
\hline Illiterate & 29 & 64.4 & 25 & 65.8 & 2 & 11.8 & \multirow{4}{*}{$0.045^{*}$} \\
\hline Read and write & 16 & 35.6 & 8 & 21.1 & 7 & 41.2 & \\
\hline Basic education & 0 & 0.0 & 4 & 10.5 & 5 & 29.4 & \\
\hline University & 0 & 0.0 & 1 & 2.6 & 3 & 17.6 & \\
\hline
\end{tabular}

Table (4): Relationship between QOL level and patient's occupation. 2014.

\begin{tabular}{|c|c|c|c|c|c|c|c|}
\hline \multirow{3}{*}{ Occupation } & \multicolumn{6}{|c|}{ QOL level } & \multirow{3}{*}{ P. value } \\
\hline & \multicolumn{2}{|c|}{$\operatorname{Low}(n=45)$} & \multicolumn{2}{|c|}{ Moderate $(n=38)$} & \multicolumn{2}{|c|}{ High $(n=17)$} & \\
\hline & No. & $\%$ & No. & $\%$ & No. & $\%$ & \\
\hline Not work & 20 & 44.4 & 7 & 18.4 & 2 & 11.8 & \multirow{5}{*}{$0.009 * *$} \\
\hline House wife & 9 & 20.0 & 14 & 36.8 & 3 & 17.6 & \\
\hline Literal work & 15 & 33.3 & 13 & 34.2 & 3 & 17.6 & \\
\hline Employee & 1 & 2.2 & 2 & 5.3 & 9 & 52.9 & \\
\hline Student & 0 & 0.0 & 2 & 5.3 & 0 & 0.0 & \\
\hline
\end{tabular}

Part III: Multiple regression analyses between lower urinary tract symptoms and QOL scale. Table (5): Multiple correlation and model summary, 2014.

\begin{tabular}{|c|c|c|}
\hline \multirow{2}{*}{$\mathbf{R}$} & \multicolumn{2}{|c|}{ ANOVA test } \\
\cline { 2 - 3 } & $\mathbf{F}$ & P. value \\
\hline 0.89 & 39.7 & $0.001^{* *}$ \\
\hline
\end{tabular}

Table (6): Coefficients of multiple regression analysis between lower urinary tract symptoms and QOL, 2014

\begin{tabular}{|l|c|c|}
\hline \multicolumn{1}{|c|}{ Items } & t & Sig. \\
\hline Have urinary frequency? & -3.528 & $0.001^{* *}$ \\
\hline Have urinary incontinence? & -2.943 & $0.004^{* *}$ \\
\hline Have urination urgency? & -3.540 & $0.001^{* *}$ \\
\hline Have nocturia? & -2.406 & $0.018^{*}$ \\
\hline Have hesitancy? & -1.111 & 0.270 \\
\hline Have double voiding? & -1.268 & 0.208 \\
\hline Suffer from intermittent flow of urine? & -1.499 & 0.137 \\
\hline Have weak flow stream? & -1.586 & 0.116 \\
\hline
\end{tabular}

This study shows reveals the more than half of the patient in study $61 \%$ was with age of 50 years and more, $54 \%$ were male, $56 \%$ were illiterate, $55 \%$ were studied patients were in sedentary life either without work or house wife and $78 \%$ were married.

Table (1) : illustrate that $70 \%$ of studied samples were suffer from urinary frequency, $58.6 \%$ of them were less than 10 times a day frequent. As regards getting frequent urination in the night $64.3 \%$.

Regarding urinary incontinence, demonstrates that $41 \%$ of studied samples were urinary incontinence, $51.2 \%$ of them were months long has suffered from urinary incontinence, while $29.3 \%$ of them were days long, but $19.5 \%$ were years long. $70.7 \%$ of patients whose gets urinary incontinence were less than 3 times a day, while $29.3 \%$ of them were more than 3 time a day. $30 \%$ of them gets urinary incontinence during coughing or sneezing, or carry heavy object.

Regarding urgency and nocturia as shows that $70 \%$ of studied samples were urgency, $62.9 \%$ of them were becoming urgency before treatment. Demonstrates that, $72 \%$ of studied samples were nocturia, $68.1 \%$ of them were nocturia less than 3 times /night. $38 \%$ of studied samples were having hesitancy. 
Table (2) : 77.8\% of patients who's QOL low were of 50 years and more with a statistically significant difference $(p$. value $=0.011)$.

Table (3) : $64.4 \%$ of patients who's QOL low were illiterate with a statistically significant difference (p. value $=0.045$ ).

Table (4) : $44.4 \%$ of patients who's QOL low were without work with a statistically significant difference $(\mathrm{p}$. value $=0.009)$.

Table (5) : there is a positive strong multiple correlation between symptoms and QOL ( $\mathrm{r}=0.89)$ with significant statistically difference in multiple comparison between lower urinary tract symptoms and QOL using ANOVA test that means the symptoms affects the QOL.

Table (6) : shows that the most lower urinary tract symptoms risk factors affect the QOL is urinary frequency, urinary incontinence, urgency and nocturia with negative $t$ value that means the symptoms decrease QOL and significant statistically difference at $\mathrm{p}<0.05$.

\section{Discussion}

Based on the results of the current study, more than a half of studied patients were ranged between 50-65 years of age, more than half of the studied the patients were males; more than half were illiterates, more than half of the studied patients were in sedentary life without working or house wives and more than two thirds of the studied patients were married.

As regard to age, this study finding was supported by Mosterd and Hoes, (2007) who reported, that persons younger than 50 years are hardly ever found heart failure, but in those older than 50 years the prevalence and incidence increase progressively with age.

Concerning the gender, the result is in line with Eaker et al, (2010) who reported that most of the patients with chronic heart failure are male. The finding are nearly similar to the results of Indian, (2010) who found in his study that the patients who have chronic heart failure, men $(11.8 \%)$ are slightly more likely than women $(9.0 \%)$ and increasing age corresponds with higher $\mathrm{CHF}$ prevalence for both genders.

According to educational level the present study finding was supported by Christensen et al., (2011) who concluded that the relationship between educational level and hospital admission for chronic heart failure with an almost 50\% lower risk with the highest level of education compared with the lowest in both men and women. The current results agree with Mostafa, (2008) who reported patients with chronic heart failure that the majority of the studied samples were illiterates.

As regard to occupation, the present study results are in line with Bugajska et al., (2009) who reported that few numbers of the patients with chronic heart failure are engaged in regular physical activity they are working. This finding is nearly similar to the results of Chacon et al., (2008) who found that (54.8\%) of the studied sample were not working and housewives. As regard to marital status, the present study finding was supported by Eaker et al, (2010) who reported that married men were significantly related to chronic heart failure, because that their wife's work was disruptive to their home life because she would come home upset with her work. This finding disagrees with Robert et al., (2014) who reported that the married, was not associated with outcomes in heart failure patients.

According to lower urinary tract symptoms, the results in the present study revealed that, most of the patients suffer from LUTS. As the results indicate the more than two-thirds of the studied sample were suffering from frequency urination, more than half of them less than 10 times and more than two-thirds of them getting urinary frequency at night. These results are supported with Tannenbaum and Johnell, (2013) who stated that lower urinary tract symptoms is much higher, urinary frequency was $60 \%$ of men and women of patients with heart failure.

As regarding the urinary incontinence, results presented that more than one-third of the patients have urinary incontinence. This finding are in the same line with Rita and Hwang, (2013) who emphasized that the urinary incontinence were prevalent in patients with chronic heart failure approximately $45 \%$ were incontinent 2 to 3 daily. This study finding was supported by Bouwman et al., (2014) who found that the urinary incontinence seem to be related chronic heart failure.

As regards to urgency this study results show more than two-thirds of patients have urgency and increasingly urinary urgency before treatment. These findings are in the same line with Chiu, (2012) who mentioned that the occurrence of urgency urination was $67 \%$ in the patients with chronic heart failure.

The present study mentioned that, more than twothirds of the studied patients were having nocturia less than 3 times. This result is in agreement with Redeker et al., (2012) who recommended that, nocturia is common among patients with heart failure (HF) and was closely associated with poor sleep quality $75 \%$. Also, this finding is supported by, Soufer, (2009) who stated that, excessive urination at night (nocturia) in heart failure caused by fluid redistribution while a person is sleeping lying down. 
As regards to voiding urination symptoms, the finding of the present study showed that hesitancy. These findings are in the same line with. Batista et al., (2007) who found that a history of medical diseases such as chronic heart failure can cause voiding symptoms by their effects on the lower urinary tract or fluid mobilization.

As regards to the relationship between patient's characteristics and quality of life level, the present study illustrates that there is statistically significant differences between quality of life of the studied patients and their age, the present study shows that low QOL increased with age, of 50 years and more. This finding is in the same line with Hoekstra et al., (2013) who found that low QOL scores increased with age in patient's heart failure.

The current study illustrates that there are statistically significant differences between quality of life of the studied patients and their education. The present study shows that there is low QOL with illiterate. This finding is in the same line with Heydar et al., (2012) who found that there is low QOL with illiterate, and $84 \%$ had a low level of quality of life with chronic heart failure.

The present study illustrates that there is a statistical difference between quality of life of the studied patients and their occupation. The present study shows that low QOL increased with not work. This finding is consistent with Cristina et al., (2011) who found that in the QOL assessment through chronic heart failure they were not working $83.0 \%$.

Finally, it can be concluded that there is as strong multiple correlation between lower urinary tract symptoms and quality of life, Storage symptoms as such (frequency, incontinence, urgency and nocturia) have more effect on QOL of chronic heart failure patients.

\section{Conclusion and Recommendations}

\section{Conclusions}

Based on the result of the present study, it can be concluded that, lower urinary tract symptoms have effect on the quality of life among patients with chronic heart failure. It can be concluded that, there is strong correlation between lower urinary tract symptoms such as incontinence, nocturia, frequency, urgency and chronic heart failure.

The study recommended that

- Patients should be provided with sufficient information about urinary tract symptoms with heart failure and full health education of quality of life before discharging from the hospital.

- Each patient should receive map and appointment card indicating the time, day, and date of the follow- up which is schedualized approximately 2-3 weeks following discharge.

- Establishment of teaching program to provide health education for patients and discharge planning service that starts with the hospitalization of patients.

\section{Acknowledgements}

We express great thanks to all patients who kindly participated in this study for their cooperation.

\section{References}

1. Aroussy, W., (2008): Heart Failure in Egyptians Does Hypertension has a role Heart Failure in Egypt - NHP data - Kasr ElAini Hospitals : PP 1-19.

2. Assiut University Hospital records, (2012): Taking on 2013.

3. Batista J., Molinuevo, B., \& Pardo, Y., (2007): Impact of lower urinary tract symptoms on quality of life using Functional Assessment Cancer Therapy scale. Urology, 69 (2), PP 285288. doi:10.1016/j.urology.2006.09.054.

4. Bouwman, I., Kollen, B., Nijman, R., \& Heide, W., (2014): Is lower urinary tract symptoms in men associated with cardiovascular diseases in a primary care population: a registry study? BMC Family Practice, 15, PP 9.

5. Bugajska, J., Michalak, J., Jedryka, A., Sagan, A., \& Konarska, M., (2009): Coronary heart disease risk factors and cardiovascular risk in physical workers and managers. International Journal of Occupational Safety and Ergonomics, 15(1), PP 35-43. Retrieved from http://www.ncbi.nlm.nih.gov/pubmed/19272238. (2009).

6. Canbaz S., Sunter T., Dabak S., and Peksen Y., (2003): The Prevalence of Chronic Diseases and Quality of Life in adult People in Samsun, Turk Journal of Medical science, Vol 33, No 10, PP 335-340.

7. Chacon E., Ulloa C., and Bixby L., (2008): Factors associated with heart failure prevalence, unawareness and treatment among Costa Rican elderly, Public Health, Vol 8, PP 275.

8. Chiu. A., (2012): High Classification of Chronic Heart Failure Increases Risk of Overactive Bladder Syndrome and Lower Urinary Tract Symptoms. V (20). Pp 182 - 196.

9. Christensen, S., Mogelvang, R., Heitmann, M., \& Prescott, E., (2011): Level of education and risk of heart failure: a prospective cohort study with echocardiography evaluation. European Heart Journal, 32(4), PP 450-8. doi:10.1093/eurheartj/ehq435.

10. Cristina, I., Saccomann, R., Cintra, F., Cecilia, M., \& Gallani, B., (2011): Quality of 
life in adults with heart failure : assessment with a specific instrument. 24(2), PP 179-184.

11. Eaker, E., Sullivan, L., Kelly-Hayes, M., Agostino, R., \& Benjamin, E., (2010): Marital status, marital strain, and risk of coronary heart disease or total mortality: the Framingham Offspring Study. Psychosomatic Medicine, 69(6), PP 509-513.

12. Francis, L., Reid, J., Murray, S., \& Denvir, M. (2010): Quality of life in patients with chronic heart failure and their carers: a 3-year follow-up study assessing hospitalization and mortality. European Journal of Heart Failure, 12(9), PP 1002-1008.

13. Heydar C., Khani S., and Shahhosseini, Z., (2012): Health-related quality of life of elderly living in nursing home and homes in a district of Iran: Implications for policy makers, Indian Journal of Science and Technology, vol 5, No 5, PP 278 -278.

14. Hoekstra, T., Jaarsma, T., Veldhuisen, D. J., Hillege, H., Sanderman, R., \& Lesman, I., (2013): Quality of life and survival in patients with heart failure. European Journal of Heart Failure, 15(1), PP 94-102.

15. Indians, A., \& Natives, A. (2010): National Resource Center on Native American Aging Center for Rural Health Native Aging facts Congestive Heart Failure among Older Findings : One of Ten American, Vol 43, No 2. PP 28-36.

16. King C., \& Hinds P., (2004): Quality of life from nursing patient perspectives theory, research, pactice. Jones and Bartlett publishers, London, Singapore, Pp: 23-34.

17. Kuyken, K, (1994): used Scoring system of quality of life and analyses showed a correlation coefficient of more than 0.4-0.8.

18. Kwong, N., (2010): Quality-of-life measures in chronic diseases. Health Technology Assessment (Winchester, England),V.(5),pp.(4-15).Retrieved from,

http://www.ncbi.nlm.nih.gov/pubmed/1126242 1. (2010).

19. Mostafa M., (2008): Study of heart failure patient in outpatient clinics in sohag university hospital, Faculty of medicine- internal medicine Department, PP 4-17.

20. Mosterd, A., \& Hoes, A., (2007): Clinical epidemiology of heart failure. Heart (British Cardiac Society), 93(9), PP 1137-1146.

21. Redeker, N., Adams, L., Berkowitz, R., Blank, L., Freudenberger, R., \& Rapoport, D., (2012): Nocturia, sleep and daytime function in stable heart failure. Journal of Cardiac Failure, 18 (7), PP $569-75$. doi:10.1016/j.cardfail.2012.05.002.
22. Rita, Z., \& Hwang, P., (2013): Frequency of urinary incontinence in people with chronic heart failure. The Journal of Acute and Critical Care Volume 42, Issue 1, PP 26-31.

23. Robert J., Phillip, V., \& Jerome F., Steven K., (2014): socioeconomic status, marital status and outcomes in heart failure: findings from hf action; 63 pp 12- 15 .

24. Schulze, P., (2008): New diagnostic tool in chronic heart failure. V. (7). PP 11-17.

25. Smeltzer, S., Hinkle, J., and Cheever, K., (2010): textbook of medical-surgical nursing, Chapter 30, ${ }_{11}^{\text {th }}$ ED. Philadelphia: Lippincott Williams \& Wilkins .PP 946-958.

26. Soufer, R., (2009): Heart failure. And present with nocturia of lower urinary tract symptoms. Urology, $79 \quad$ (2), PP 260-265. doi:10.1016/j.urology.2011.10.020.

27. Tannenbaum, E., \& Johnell, D., (2013): Managing Therapeutic Competition in Patients with Heart Failure, Lower Urinary Tract Symptoms and Incontinence. Drugs \& aging. (31) PP 44-52,

28. Zarrinkoub, S., Ljunggren, G., \& Kahan, T., (2013): The epidemiology of heart failure, based on data for inhabitants in Sweden. European Journal of Heart Failure, v. (15) PP. 995-1002. 